\section{AB0827 COMPARISON OF THE CAPABILITY OF RADIAL BONE MINERAL DENSITY AND CALCANEAL QUANTITATIVE ULTRASOUND VARIABLES IN THE IDENTIFICATION OF MEN WITH OSTEOPOROSIS}

A. Oral, D. Sindel, A. Yaliman, S. Asghari Kaleibar, S. Esmaeilzadeh. Physical Medicine and Rehabilitation, Istanbul University Istanbul Faculty of Medicine, Istanbul, Turkey

Background: Bone mineral density (BMD) as measured by dual-energy X-ray absorptiometry (DXA) is considered the gold standard for the management of osteoporosis. Recently, quantitative ultrasound (QUS), which is easy to use, inexpensive, portable, does not use ionizing radiation, and has also been shown to provide information about bone quality and to predict fracture risk, has gained growing interest in this area.

Objectives: The aim of this study was to compare the capability of one-third radius (33\% radius) DXA BMD measurements and calcaneal QUS (cQUS) variables for identifying axial osteoporosis as measured by DXA in men.

Methods: Axial BMD measurements at the lumbar spine and at the hip (femoral neck and total hip), 1/3 radius $B M D$ of the non-dominant forearm were made using DXA and cQUS variables at both sides as measured twice were obtained in 179 men aged between 24 and 85 years. Osteoporosis was defined based on the WHO criteria in men aged 50 and over, a man having been considered as osteoporotic in the presence of a T-score $\leq-2.5$ in any of the axial regions measured. For defining axial osteoporosis or BMD below the expected range for age, Z-scores of $\leq-2.0$ were used in men younger than the age of 50 years. Receiver operating characteristic $(\mathrm{ROC})$ analysis was used to assess the osteoporosis identification capability of measurements.

Results: The areas under ROC curves (AUCs) for $1 / 3$ radius BMD, its T-score, the lowest means (as calculated as the mean of the two calcaneal QUS measurements for each heel) of quantitative ultrasound index (QUI), QUI T-score, broadband ultrasound attenuation (BUA), speed of sound (SOS), and estimated heel BMD (eBMD) for identifying axial osteoporosis or BMD below the expected range were found as $0.755,0.767,0.760,0.758,0.717,0.768$, and $0.764(p<0.001$ for all), respectively.

Conclusions: In conclusion, AUCs pointed to similar (for QUI, QUI T-score, and eBMD) or even better (for SOS) osteoporosis discriminative capability of cQUS variables in comparison to radial DXA BMD variables. These findings may have implications that CQUS variables, particularly SOS, may be used for the identification of osteoporosis in men whose axial BMD cannot be measured by DXA due to certain circumstances as well as in circumstances where DXA is not available.

References:

[1] Marín F, González-Macías J, Díez-Pérez A, Palma S, Delgado-Rodríguez M. Relationship between bone quantitative ultrasound and fractures: a metaanalysis. J Bone Miner Res 2006;21:1126-35.

[2] Moayyeri A, Adams JE, Adler RA, Krieg MA, Hans D, Compston J, Lewiecki EM. Quantitative ultrasound of the heel and fracture risk assessment: an updated meta-analysis. Osteoporos Int 2012;23:143-53.

[3] Kilappa V, Moilanen P, Xu L, Nicholson PH, Timonen J, Cheng S. Lowfrequency axial ultrasound velocity correlates with bone mineral density and cortical thickness in the radius and tibia in pre- and postmenopausal women. Osteoporos Int 2011;22:1103-1113.

Disclosure of Interest: None declared

DOI: 10.1136/annrheumdis-2017-eular.6686

\section{AB0828 MAJOR RISK FACTORS OF OSTEOPOROSIS IN RA FEMALE PATIENTS WITH NORMAL MENSTRUAL CYCLE}

E.A. Taskina, L.I. Alekseeva, I.S. Dydykina, M.M. Podvorotova, A.V. Smirnov, S.I. Glukhova, E.L. Nasonov. V.A. Nasonova Research Institute of Rheumatology, Moscow, Russia, Moscow, Russian Federation

Background: Only postmenopausal women were in the researcher's focus in the majority of publications on osteoporosis (OP) risk factors (RF) in RA female patients (pts). Meanwhile the data on OP RF in menstruating women presented in the rare available papers are not consistent.

Objectives: To identify the major OP RF in RA female pts with normal menstrual cycle.

Methods: $51 \mathrm{RA}$ (based on ACR criteria) female pts with normal menstrual cycle aged 20 to 51 years (mean age $41,1 \pm 7,9$ ) were examined. The following info was included in each individual pts' files: anthropometric parameters, social and demographic data, case history, clinical examination and lab findings, traditional OP RF, pts' joint status, comorbidities status, pain intensity assessments and VAS evaluation of pts' general health status. Axial bone mineral density (BMD) was measured with DEXA scan using Z-score calculator. Based on the OP status all pts were divided into 2 groups:pts with OP-16 (31,4\%), and pts without OP-35 $(68,6 \%)$.

Results: Comparative analyses of the groups showed that: OP pts were younger vs the pts without OP $(36,9 \pm 10$ vs $42,8 \pm 6,3$ years, $p=0,02)$. Disease duration was comparable in both groups. Clinical manifestations of inflammation activity (mean DAS 28 score and hsCRP) were statistically significantly more pronounced in the OP group vs the pts without OP $(4,91 \pm 1,39$ vs $4,19 \pm 1,06, p=0,049 ; 27,8(10,8-$ $43,5)$ vs $7,4(1,4-22,7) \mathrm{mg} / \mathrm{L}, p=0,02$, respectively). High DAS 28 (50 vs 20,6\%,
$\mathrm{RR}=2,43,95 \% \mathrm{Cl} 1,07-5,53, p=0,03)$ scores were more often documented in the OP pts. Pronounced feet and hand bone destruction based on the radiographic findings was documented in the majority of pts in both groups, although in the OP pts the joint space narrowing counts $(97(62,5-121)$ vs $73,5(53-87)$, $p=0,02)$ and the total Sharp score $(98(64,5-183)$ vs $89,0(63-112), p=0,03)$ were statistically significantly higher. The OP pts were more often administered oral GCs $(81,3$ vs $37,1 \%, R R=2,19,95 \% \mathrm{Cl} 1,34-3,57, p=0,004)$, as well as GCs - pulse therapy $(56,3$ vs $25,7 \%$, RR=2,18,95\% Cl 1,08-4,45, p=0,04), had higher GCs cumulative dose $(18,8(8,1-30,7)$ vs $6,4(0,8-14,1) \mathrm{g}, p<0,01)$, higher GC daily dose at the time of examination $(8,8(6,3-10)$ vs $5(3,8-6,3) \mathrm{mg} / \mathrm{day}$, $p=0,01)$ and higher average daily dose in the previous year $(8,8(5-10)$ vs 3,8 $(2,5-6,3) \mathrm{mg} /$ day, $p=0,01)$ versus the pts without OP. Analysis of traditional RF (low body weight/BMI, long immobilization periods, smoking, family history of OP and others) showed no difference between the two groups. Discriminant analysis revealed the following major OP RF in the RA female pts before menopause: RA activity (based on the Das 28 score) and GCs dose at the time of examination (given GCs therapy lasts $\geq 3$ months). Meanwhile the patient's body weight and age at the onset of RA were identified as protective factors for BMD. Based on the abovementioned risk and protective factors and the derived coefficients the authors designed a formula allowing to predict of OP in female RA pts before menopause with high accuracy (area under the ROC-curve $=0,833$ ). The model accuracy is $85,1 \%$.

\begin{tabular}{|c|c|}
\hline Factors & $\begin{array}{l}\text { Discriminant } \\
\text { function } \\
\text { coefficients }\end{array}$ \\
\cline { 2 - 2 } $\begin{array}{c}\text { RA activity } \\
\text { (DAS 28) }\end{array}$ & 0,667 \\
\hline $\begin{array}{c}\text { GCs dose at the time of } \\
\text { examination }\end{array}$ & 0,257 \\
\hline Age at RA onset & $-0,09$ \\
\hline Body weight & $-0,034$ \\
\hline Constant & 1,319 \\
\hline
\end{tabular}

Conclusions: RA activity and GCs dose (GCs therapy duration $\geq 3$ months) were identified as the major OP RF in young RA female pts before menopause, thus adequate and timely therapy aimed at obtaining RA control and achieving remission should be considered as key OP prevention strategy.

Disclosure of Interest: None declared

DOI: 10.1136/annrheumdis-2017-eular.2312

\section{AB0829 BONE METABOLISM IN LIVER TRANSPLANT PATIENTS TWO-YEAR STUDY. INFLUENCE OF MEDICAL INTERVENTION PRIOR TO SURGERY AND ANTIRESORPTIVE TREATMENT}

E. Labrador Sánchez ${ }^{1}$, E. Grau Garcia ${ }^{1}$, K. Arévalo Ruales ${ }^{1}$, J.J. Fragio Gil ${ }^{1}$, R. González Mazarío ${ }^{1}$, C. Alcañiz Escandell ${ }^{1}$, I. Cánovas Olmos ${ }^{1}$, I. Chalmeta Verdejo ${ }^{1}$, C.M. Feced Olmos ${ }^{1}$, L. Gonzalez Puig ${ }^{1}$, J. Ivorra Cortes ${ }^{1}$, I. Martínez Cordellat $^{1}$, C. Nájera Herranz ${ }^{1}$, R. Negueroles Albuixech ${ }^{1}$, J.E. Oller

Rodriguez ${ }^{1}$, F.M. Ortiz-Sanjuan ${ }^{1}$, E. Vicens Bernabeu ${ }^{1}$, A. Villota Bello ${ }^{2}$, V. Fornés Ferrer ${ }^{3}$, D. Hervás Marín ${ }^{3}$, D. Moya Nájera ${ }^{4}$, A. Moya Herraiz $^{5}$ J.A. Román Ivorra ${ }^{1,2}$. ${ }^{1}$ Rheumatology Department, HUP la Fe; ${ }^{2}$ Medical School, UCV; ${ }^{3}$ Biostatistic Unit, IIS la Fe; ${ }^{4}$ Health and Sport Group, UV; ${ }^{5}$ Hepatology Department, HUP la Fe, Valencia, Spain

Background: Osteoporosis is a frequent complication in patients with chronic liver diseases, mainly in advanced stages or with evidence of cholestasis. During the first few months after liver transplant (LT) it seems that there is an accelerated bone mass loss and greater fracture risk.

Objectives: To study the antiresorptive treatment effect in bone metabolism in patients undergoing LT and to evaluate whether medical intervention prior to LT decreases the risk of osteoporosis

Methods: We recruited patients from the LT Protocol of Osteoporotic Risk Assessment. The patients were evaluated 3-6 months before surgery, shortly after transplant (month 0) and 6-12-18-24 months after surgery. Data of bone metabolism biomarkers, densitometric values and antiresorptive treatment was collected. Biostatistical analysis with R (3.3.2.) was performed.

Results: We selected 163 LT patients of which 86 completed 24 months follow-up. From the total cohort, $77.8 \%$ were men and the mean age at transplantation $54.53 \pm 9.4$ years old. $92.6 \%$ of patients were supplemented with vitamin D after surgery and $19.6 \%$ initiated antiresorptive treatment. We observed that 25-OHVitamin D, PTH, beta-CTX and P1NP levels were corrected through the follow-up. T-score during the first year of follow-up decreased slightly and at 24 months the tendency was towards increase. This pattern was stronger in lumbar spine (t-score $-1.48 \pm 1.34$ after surgery and $-1.28 \pm 1.06$ at 24 months). Statistical analysis showed that antiresorptive treatment significantly influence lumbar and hip densitometric values $(\mathrm{P}<0.001$ and $\mathrm{P}<0.001$ respectively) as well as $\mathrm{P} 1 \mathrm{NP}$ levels $(P=0.003$ and $P=0.012$ respectively). Moreover, obesity $(P=0.0004)$, as well

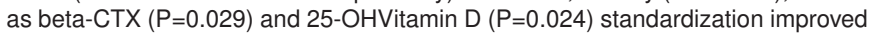
hip densitometric values. Finally, LT patients evaluated before surgery showed better lumbar densitometric values than those evaluated after the transplant $(P=0.007)$. 